\title{
EXPERIMENTAL INVESTIGATIONS IN VERTICAL VIBRATION DAMPING OF AGRICULTURAL AGGREGATE OF BLOCK-MODULAR TYPE
}

\author{
Volodymyr Bulgakov $^{1}$, Volodymyr Kuvachov ${ }^{2}$, Semjons Ivanovs ${ }^{3}$, Viktor Melnyk ${ }^{4}$ \\ ${ }^{1}$ National University of Life and Environmental Sciences of Ukraine, Ukraine; \\ ${ }^{2}$ Tavria State Agrotechnological University, Ukraine; \\ ${ }^{3}$ Latvia University of Life Sciences and Technologies, Latvia; \\ ${ }^{4}$ Kharkiv Petro Vasylenko National Technical University of Agriculture, Ukraine \\ semjons@apollo.lv, viktor_melnik@ukr.net
}

\begin{abstract}
Under conditions of real operation of block-modular aggregates continuous oscillations of external disturbances lead to a decrease in their technical and operational indicators and an increase in specific fuel consumption per unit of the work performed. Evaluation of the performance indicators of a block-modular agricultural aggregate, based on the MTZ-82 serial tractor with a technological module was carried out on the basis of laboratory-field research on ploughing cereal stubble. These investigations were performed by means of a strain gauge measuring complex that recorded signals on a PC, using an analogue-to-digital converter. The results obtained were processed in the Matlab program. Creation of a rational elastic-damping connection between the tractor and the technological module allows obtaining the desired amplitude-frequency and correlation-spectral characteristics of vertical oscillations of a modular agricultural aggregate, reducing the dispersion of the torque oscillations on the tractor power take-off shaft by 10 times. An elastic-damping connection between the tractor and the technological module with a drag coefficient of $1.65 \mathrm{kN} \cdot \mathrm{s} \cdot \mathrm{m}^{-1}$ on ploughing has made it possible to reduce by 3-4 times the dispersion of vertical vibrations of the block-modular aggregate, to increase its performance by $6 \%$.
\end{abstract}

Keywords: block-modular aggregate, vibration, oscillations, damping.

\section{Introduction}

An increase in the energy saturation of the tractor fleet in agriculture is a global trend [1]. However, many years of experience in operating agricultural machine-and-tractor aggregates showed that often the increase in the energy saturation of tractors did not give a proportional increase in their efficiency and increased energy consumption per unit of the performed work [2; 3]. It has been theoretically and experimentally proved that an increase in the efficiency of the machine-and-tractor aggregates by increasing the width of operation (increasing the tractive effort of the tractor), or by increasing its speed has an agrotechnical limit [3;4]. A perspective direction in the development of tractor building, which means creation of traction-driven agricultural aggregates, has not yet been sufficiently studied. Of particular interest is the formation of such aggregates according to the block-modular principle, using technological modules with the driving wheels [5-7].

Under the conditions of real operation of the block-modular aggregates continuous fluctuations of external disturbances lead to a decrease in their technical and operational indicators and an increase in the specific fuel consumption per unit of the work performed [8;9]. A positive by-effect of the technological module is vibration damping of the block-modular aggregate, created by inertia of its weight and the resistance force of the agricultural implement. Investigation of the smooth running of mobile power facilities, transport and machine-and-tractor aggregates, in order to improve their dynamic characteristics, are given in the works by many scientists [6-12]. In particular, they have proved that the vertical vibrations of agricultural aggregates lead to a change in the dynamic radius of the tractor wheels, and with it, its adhesion weight. The angular speed of rotation of the engine shaft of tractors from the level of their vibration load decreases in this case by $10-25 \mathrm{~s}^{-1}[6]$. The variable moment of resistance on the shaft of the tractor engine, due to the nonlinearity of its speed characteristics, leads to incomplete use of power and a decrease in the energy costs by $6-18 \mathrm{~kW}$ [4-6]. But a decrease in the forward speed of the movement of agricultural aggregates decreases by $0.4 \mathrm{~m} \cdot \mathrm{s}^{-1}$, which ultimately reduces the productivity of the work [6].

A peculiarity of the smooth running of the block-modular aggregate is that the angular oscillations of the technological module (due to their smallness in comparison with the vertical ones) can be neglected [6]. But, due to the efficiency of the draft hitch, the galloping of the tractor significantly less affects the technical and operational performance of the aggregate than the forward vertical vibrations. The tractor and the technological module make forced proper vertical vibrations, caused by irregularities

DOI: 10.22616/ERDev.2021.20.TF136 
in the longitudinal profile of the agricultural background. As a result, an interaction of oscillations of the technological module arises upon the tractor, and vice versa. The significant oscillations of the blockmodular agricultural aggregate in a vertical plane worsen the operating conditions of the operator, reduce the reliability and productivity of the work [6;9]. However, the existing investigations and developments do not consider the problem of the impact of the stiffness of the connection of the technological part of the aggregate with the energy part upon the characteristics of the oscillations of the aggregate as a whole.

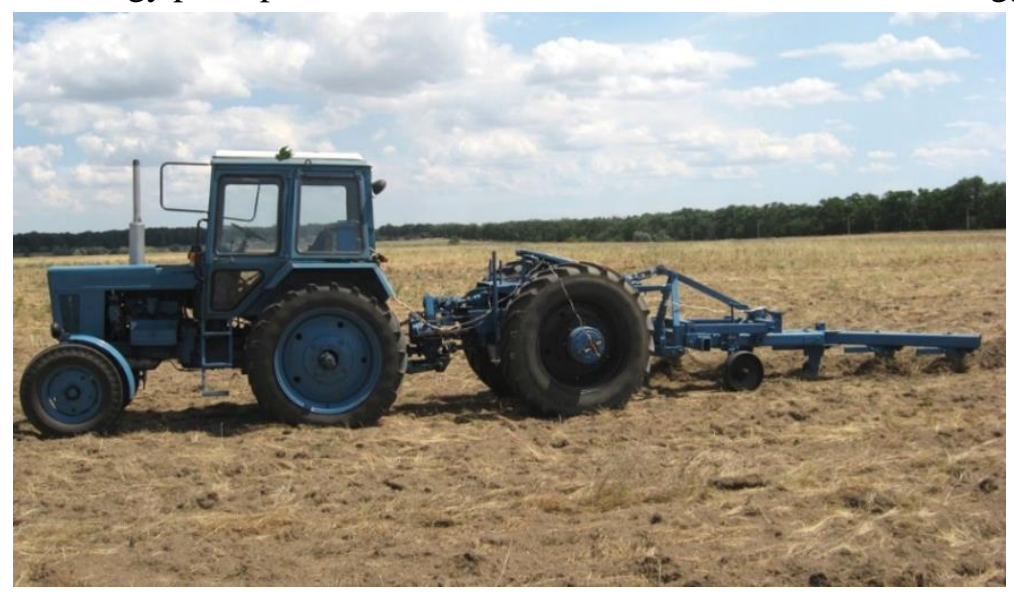

Fig. 1. Ploughing block-modular agricultural aggregate

A real assessment of the efficiency of using a block-modular agricultural implement can be obtained only when satisfactory smoothness of its movement is ensured. An insufficiently strict approach to solving this issue can adversely affect a number of operational indicators that ultimately determine the work productivity, specific fuel consumption, material costs and the labour intensity of performing the agrotechnical operations. In most cases the methods for studying the smoothness of the movement are aimed at determining the root-mean-square values of the vibration load parameters, which are integral criteria in certain frequency ranges. A qualitative analysis of the structure and connectivity of the oscillatory processes, related to different rigidity of the connection of the energy part with the technological part, is not given at all in the study of the vibration load of the dynamic systems. This complicates the choice of the vibration protection systems for a modular agricultural aggregate at the designing stage and during the operation of the existing structures when increasing their smoothness of movement. The purpose of this investigation is experimental research of damping of the vertical oscillations of a block-modular aggregate, caused by the inertia of the weight of the technological module and the resistance force of the agricultural implements.

\section{Materials and methods}

Evaluation of the performance indicators of the block-modular agricultural aggregate was made on the basis of the MTZ-82 serial tractor with a technological module (its technical characteristics are presented in Table 1). The test program of the block-modular agricultural aggregate was formed, using its laboratory-field research on ploughing the cereal stubble (Fig. 1). The supporting frame of the technological module is articulated (Fig. 2). Its frontal turntable part is connected to the rods of the rear hitch of the tractor. A matching gearbox is installed on the turntable part of the frame of the modular agricultural aggregate, which synchronises the angular speed of the driving wheels of the tractor and the technological module. The articulated joint of the supporting frame of the technological module (Fig. 2) ensures mutual turning of its frontal and rear parts on a horizontal plane by an angle of $\pm 30^{\circ}$ in both directions and by an angle of $\pm 15^{\circ}$ in the transverse vertical plane when copying irregularities of the agricultural background. The vertical joint is equipped with two hydraulic cylinders that provide high directional lateral stability during operation. For aggregation with agricultural implements the technological module of the modular agricultural aggregate is equipped with a hydraulic suspension system.

Determination of the parameters of the energy assessment for the object of the research was done by the tensometric method simultaneously with the implementation of the research plan, using analogueto-digital conversion of signals with simultaneous recording of the realisations on a PC. 
Technical characteristics of the modular agricultural aggregate

\begin{tabular}{|l|c|}
\hline \multicolumn{1}{|c|}{ Name of the parameter } & Value \\
\hline Operating mass (weight) of the tractor, $\mathrm{kg}$ & 3640 \\
\hline Operating mass (weight) of the technological module (without a ballast), $\mathrm{kg}$ & 2500 \\
\hline Mass (weight) of the additional ballast to the technological module, $\mathrm{kg}$ & 1200 \\
\hline Engine power, $\mathrm{kW}$ & 62.0 \\
\hline Energy saturation of the tractor, $\mathrm{kW} \cdot \mathrm{t}^{-1}$ & 17.0 \\
\hline Energy saturation of the block-modular aggregate, $\mathrm{kW} \cdot \mathrm{t}^{-1}$ & 10.0 \\
\hline Draft resistance of the technological module (with a ballast), $\mathrm{kN}$ & 16.0 \\
\hline Longitudinal base of the tractor, $\mathrm{m}$ & 2.37 \\
\hline $\begin{array}{l}\text { Distance from the axle of the rear wheels of the tractor to the axle of the wheels } \\
\text { of the technological module, } \mathrm{m}\end{array}$ & 2.40 \\
\hline Road clearance, $\mathrm{m}$ & 1.40 \\
\hline $\begin{array}{l}\text { Wheel tires: } \\
\text { front axle of the tractor } \\
\text { rear axle of the tractor } \\
\text { bridge of the technological module }\end{array}$ & $7.5 \mathrm{R} 20$ \\
\hline
\end{tabular}

In order to improve the accuracy of the measurement parameters, which include the vertical acceleration of the aggregate, as well as the possibility of direct remote recording of the parameters with simultaneous automatic processing of the results on a PC and adjusting the process of experimental research, a hardware measuring complex was developed (Fig. 3). In order to convert electrical signals from sensors, it uses a specially designed 8-channel analogue-to-digital converter. With the help of a specially developed program realisations of signals in both the analogue and the digital form were displayed on the PC monitor screen. The frequency of the transducer signal realisation was $32 \mathrm{~Hz}$.

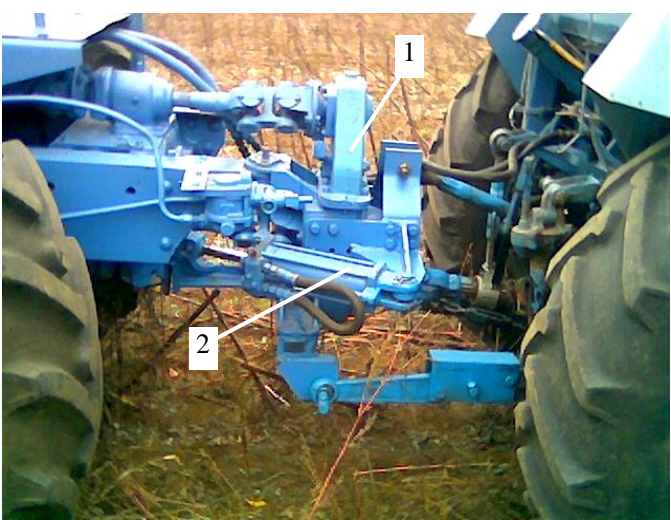

Fig. 2. Design of the frontal turnable mechanism of the technological module: 1 - matching reducer; 2 - hydraulic cylinder

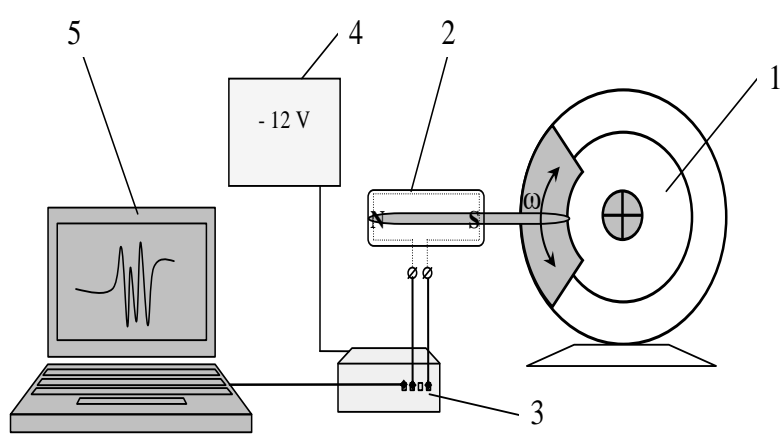

Fig. 3. Diagram of the hardware-measuring complex, used as an example, for registration of vertical vibrations: 1 - Geiger vibrograph;

2 - induction sensor; 3 - analog-to-digital converter; 4 - constant source electric current; 5 - PC

The hardware-recording complex, used in the experimental research, included an analogue-todigital converter, a storage battery, a Notebook PC, and a loop of cables from the above sensors. The total number of channels, immediately involved in the measurement of the parameters according to the experimental research plan, was five (the draft resistance of the plough, the vertical acceleration of the rear axle of the tractor of the modular agricultural aggregate, the torque on the tractor power take-off shaft, the rotation frequency of the rear wheels of the tractor, and the rotation frequency of the wheels of the technological module). The elastic-dissipative connection of the tractor and the technological module of the modular agricultural aggregate was created by throttling of the hydraulic system of the rear suspension mechanism of the tractor. This took place by installing a throttle with an adjustable flow area of a small diameter $(6,4,2,0 \mathrm{~mm})$ into one of the hydraulic lines, which connects one of the cavities 
of the main hydraulic cylinder with the hydraulic distributor. Installation of a throttle with calibrated holes in the hydraulic line corresponded to the relative reduction value of the diameter of the flow area at the point of a sudden narrowing within a range of 0-90\%. It was established by laboratory measurements that a decrease in the flow area of the hydraulic line of the rear hitch of the tractor directly proportionally changes the value of the resistance coefficient of the elastic-dissipative connection of the tractor and the technological module (Table 2).

Table 2

Relationship between the throttling degree $\Omega$ of the hydraulic system of the rear suspension mechanism of the tractor and the value of the resistance coefficient $\boldsymbol{K}_{\mu}$

\begin{tabular}{|c|c|c|c|c|c|}
\hline$\Omega, \%$ & 0 & 25 & 50 & 75 & 90 \\
\hline$K_{\mu}, \mathrm{kN} \cdot \mathrm{s} \cdot \mathbf{m}^{-1}$ & 0 & 1.00 & 1.35 & 1.65 & 1.80 \\
\hline
\end{tabular}

The torque on the power take-off shaft of the tractor of the modular agricultural aggregate was recorded using the TRAP-45 slip-on current collector. As a measuring element of the draft resistance of the plough there was used a strain gauge link of the VISKHOM design with a measurement range of 0$30 \mathrm{kN}$. Calibration of the strain gauge link was carried out on a special stand, using a DPU-5 dynamometer. The entire measurement range $(0-30 \mathrm{kN})$ was divided into 10 intervals. The loading/unload ordinates at each point were recorded on a PC through an analogue-to-digital converter. The relative error of the measurements of the draft resistance did not exceed $5 \%$. In the process of research there were applied both standard and special previously approved test methods [13]. The obtained results of the experimental investigations were processed by the methods of mathematical statistics $[14 ; 15]$ in the Matlab program.

\section{Results and discussion}

As the results of the experimental studies show, the nature of the decrease in the dispersion of the accelerations of its vertical oscillations at different degrees of elastic-dissipative coupling of the tractor and of the technological module is not the same (Fig. 4).

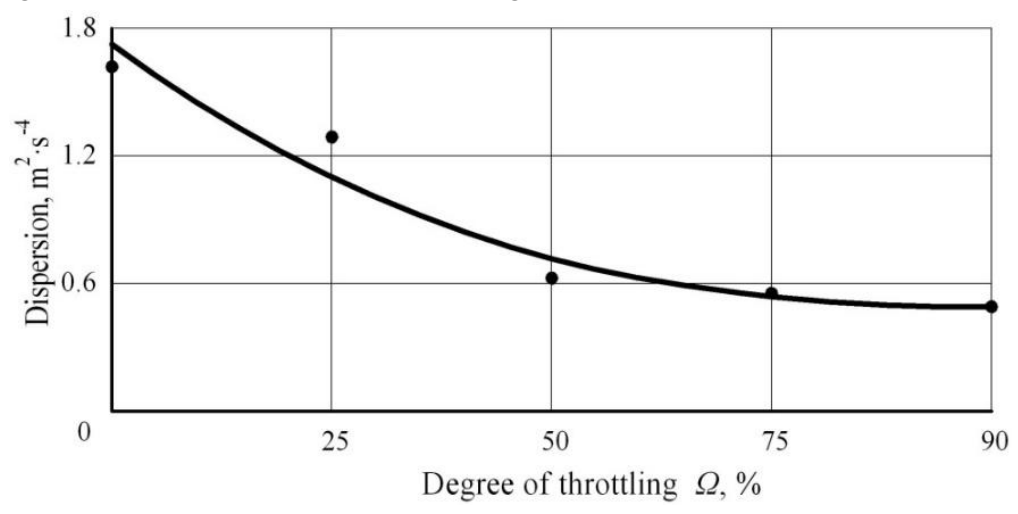

Fig. 4. Dependence of the dispersion of accelerations of vertical oscillations of the rear axle of the tractor modular agricultural aggregate upon the throttling degree $\Omega$ of the hydraulic system of the rear suspension

Intense decrease in the dispersions is observed up to the level of throttling $75-80 \%$ of the hydraulic system of the tractor rear suspension. The executed mathematical analysis of the indicated dependence showed that the critical point, which is the value of rational throttling, falls on the level of $78 \%$. A threefold decrease in the dispersions of the acceleration of the vertical oscillations of a block-modular agricultural aggregate at this level is not accidental, since, according to Fisher's F-criterion, at a significance level of 0.05 , the null hypothesis of the equality of these statistical estimates is rejected [14]. The results of the determination of the traction-and-energy indicators of the block-modular agricultural aggregate for various rigidity of the connection of two modules are presented in Table. 3 . As the results of the experiments showed, fluctuations in the draft resistance of the plough express a random function in which there are no harmonic components (Fig. 5). The main spectrum of dispersions of these fluctuations is concentrated in the frequency range $0 \ldots 18 \mathrm{~s}^{-1}$ (Fig. 6). The nature of the 
normalised correlation functions and spectral fluctuation densities of the ploughing implements (Fig. 5 and 6) confirms the fact that these fluctuations have no significant impact upon the dynamics of the vertical oscillations of a modular agricultural aggregate. Hence it follows that the result of a decrease in the dispersion of the vertical oscillations of the plough block-modular agricultural aggregate by ensuring a rational choice of rigidity of the connection between the tractor and the technological module is achieved by a certain value of throttling of the hydraulic system of the tractor rear suspension, which practically does not affect the fluctuations in the draft resistance of the plough. This is evidenced by the same nature of the fluctuation distribution density of the draft resistance of the ploughing implement both in frequency and in energy, as well as a small discrepancy in the standard deviation, which was $\pm 1.5-3.0 \mathrm{kN}$ (Table 3 ).

Table 3

Traction-and-energy indicators of the experimental aggregate

\begin{tabular}{|c|c|c|c|c|c|}
\hline \multirow[t]{2}{*}{ Indicator } & \multicolumn{5}{|c|}{$\begin{array}{l}\text { Value of the indicator for the throttling level } \Omega \text { of } \\
\text { the hydraulic system of the tractor rear suspension }\end{array}$} \\
\hline & $0 \%$ & $25 \%$ & $50 \%$ & $75 \%$ & $90 \%$ \\
\hline $\begin{array}{l}\text { Working speed of movement: } \\
\qquad \begin{array}{l}\mathrm{m} \cdot \mathrm{s}^{-1} \\
\mathrm{~km} \cdot \mathrm{h}^{-1}\end{array}\end{array}$ & $\begin{array}{l}1.52 \\
5.47\end{array}$ & $\begin{array}{l}1.72 \\
6.19\end{array}$ & $\begin{array}{l}1.56 \\
5.61\end{array}$ & $\begin{array}{l}1.67 \\
6.01\end{array}$ & $\begin{array}{l}1.67 \\
6.01\end{array}$ \\
\hline $\begin{array}{l}\text { Draft resistance of the plough: } \\
\text { the medium vallue, } \mathrm{kN} \\
\text { standard, } \pm \mathrm{kN} \\
\text { the variation coefficient, } \%\end{array}$ & $\begin{array}{c}24.15 \\
1.49 \\
9.8\end{array}$ & $\begin{array}{c}24.62 \\
3.00 \\
9.86 \\
\end{array}$ & $\begin{array}{l}24.50 \\
1.59 \\
9.08 \\
\end{array}$ & $\begin{array}{c}24.89 \\
1.94 \\
10.69 \\
\end{array}$ & $\begin{array}{c}25.34 \\
1.50 \\
11.02 \\
\end{array}$ \\
\hline $\begin{array}{l}\text { Torque on the tractor take-off shaft: } \\
\text { the medium vallue, } \mathrm{kN} \cdot \mathrm{m} \\
\text { standard, } \pm \mathrm{kN} \cdot \mathrm{m} \\
\text { the variation coefficient, } \%\end{array}$ & $\begin{array}{c}2.68 \\
1.07 \\
39.91\end{array}$ & $\begin{array}{c}2.53 \\
0.85 \\
33.59\end{array}$ & $\begin{array}{l}3.73 \\
0.37 \\
9.86\end{array}$ & $\begin{array}{l}3.44 \\
0.14 \\
3.96\end{array}$ & $\begin{array}{l}3.03 \\
0.16 \\
5.28\end{array}$ \\
\hline Efficiency for $1 \mathrm{~h}$ of the main time, ha. $\mathrm{h}^{-1}$ & 0.954 & 1.086 & 0.984 & 1.050 & 1.050 \\
\hline Specific fuel consumption, $\mathrm{kg} \cdot \mathrm{h}^{-1}$ & 18.02 & 15.02 & 16.02 & 15.02 & 13.52 \\
\hline
\end{tabular}

In further analysis of the experimental investigations from a practical point of view, it can be assumed that a change in the rigidity of the connection between the tractor and the technological module has an no significant impact upon the characteristics of the draft resistance of the agricultural implement and its impact upon the smooth movement of the modular agricultural aggregate. The influence of the rigidity of the connection of the tractor with the technological module by the nature of the oscillatory process of the torque upon its power take-off shaft is somewhat different.

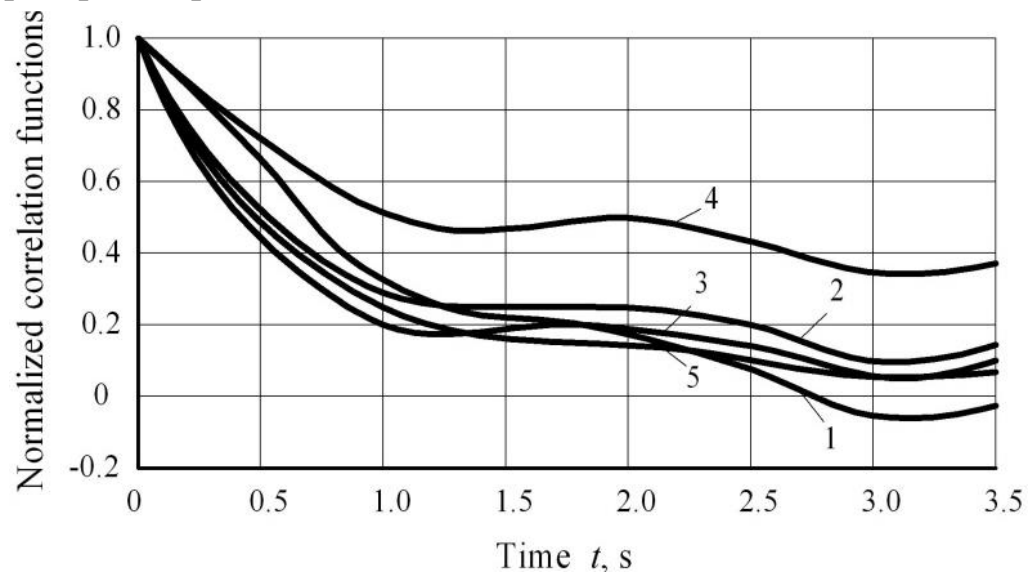

Fig. 5. Normalised correlation functions of fluctuations in the draft resistance of the plough with various throttling degrees of the hydraulic system of the tractor rear suspension:

$1-\Omega=0 \% ; 2-\Omega=25 \% ; 3-\Omega=50 \% ; 4-\Omega=75 \% ; 5-\Omega=90 \%$ 


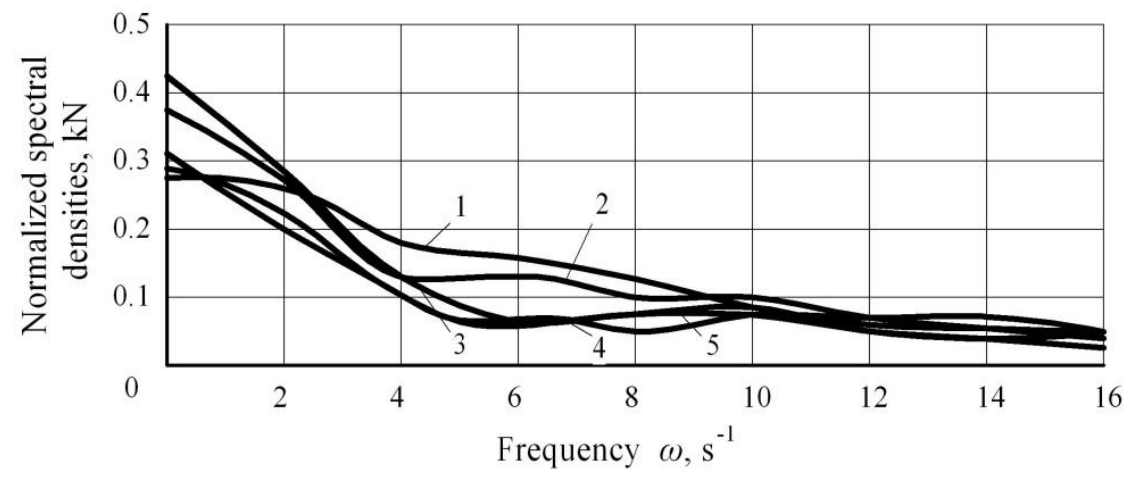

Fig. 6. Normalised spectral densities of fluctuations in the draft resistance of the plough with various throttling degrees of the hydraulic system of the tractor rear suspension mechanism:

$$
1-\Omega=0 \% ; 2-\Omega=25 \% ; 3-\Omega=50 \% ; 4-\Omega=75 \% ; 5-\Omega=90 \%
$$

Analysis of the obtained experimental data shows that the graphs of the normalised correlation functions (Fig. 7) by the nature of the process describe random functions in which there was a harmonic component, yet the degree of randomness is much higher. The main spectrum of the torque fluctuations on the tractor power take-off shaft is concentrated in the range $0-16 \mathrm{~s}^{-1}$ (Fig. 8). The pronounced maxima of the spectral density of these fluctuations indicate a more complex structure of their occurrence.

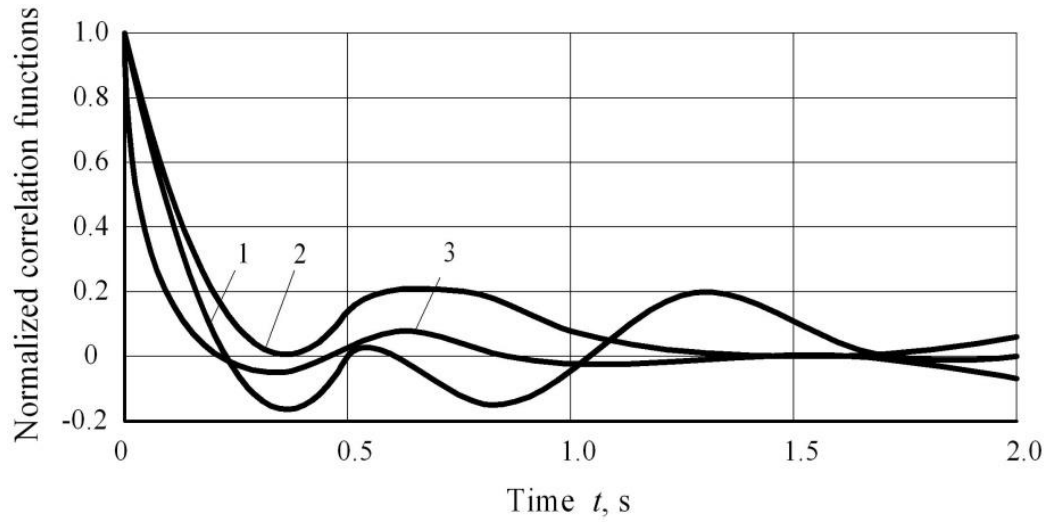

Fig. 7. Normalised correlation functions of the torque fluctuations on the tractor power take-off shaft with various throttling degrees of the hydraulic system of the rear suspension:

$1-\Omega=25 \% ; 2-\Omega=50 \% ; 3-\Omega=75 \%$

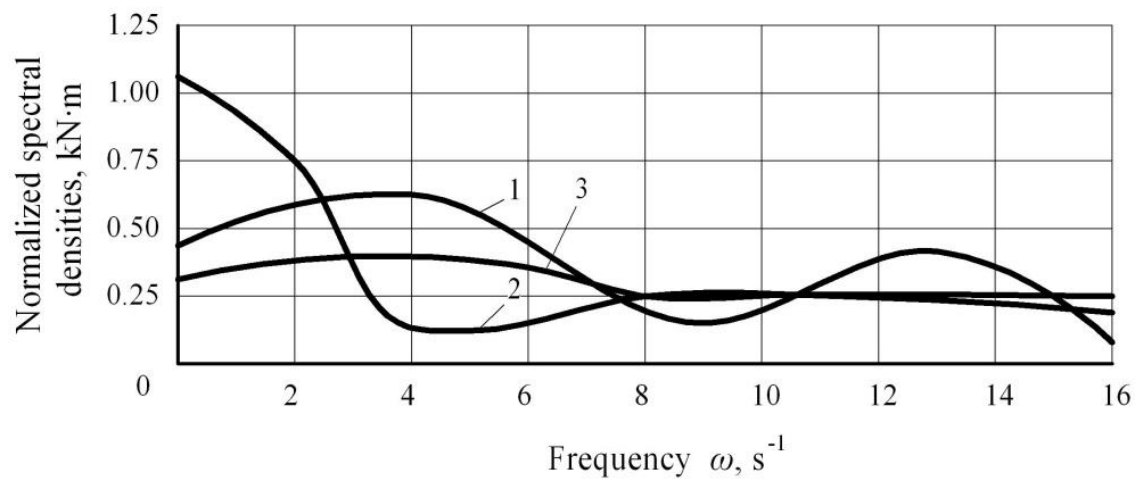

Fig. 8. Normalised spectral densities of the torque fluctuations on the tractor power take-off shaft with various throttling degrees of the hydraulic system of the rear suspension:

$$
1-\Omega=25 \% ; 2-\Omega=50 \% ; 3-\Omega=75 \%
$$

In the performed experiments the value of the not excluded systematic error was $0.1 \mathrm{~m} \cdot \mathrm{s}^{-2}$. The confidence limit of the random component of the error in the measurement result for this parameter was $0.416 \mathrm{~m} \cdot \mathrm{s}^{-2}$, and the sampling error was $0.395 \mathrm{~m} \cdot \mathrm{s}^{-2}$; deviations from the regularities, established in the process of experimental studies, did not exceed $10 \%$. 
Increasing the smoothness of the movement of the ploughing block-modular agricultural aggregate by ensuring a rational rigidity choice of a connection of the tractor with the technological module achieved by a certain throttling degree of the hydraulic system of the tractor rear suspension improves the distribution of the density of torque fluctuations on its power take-off shaft and reduces the dispersion of the fluctuations themselves. This indicates that, decreasing the dispersion of the vertical oscillations of the block-modular agricultural aggregate, the range of the standard deviation of the dynamic radius of its wheels decreases, and, with it, the adhesion weight of the tractor. The latter makes it possible to improve the draft and coupling properties of the block-modular agricultural aggregate since it allows to reduce the power consumption for its oscillations, and to increase the energy indicators. Analysis of the laboratory and field experimental studies shows that the result of the increase in the smoothness of the movement of the ploughing block-modular agricultural aggregate allows ploughing at a higher speed (Table 2). As a result, the output per $1 \mathrm{~h}$ of the main time increases in direct proportion. In addition to the increase in productivity, there was noted the fact of a decrease in the specific (per hectare) fuel consumption of the ploughing block-modular agricultural aggregate (see Table 2) by $12.4 \%$. With a confidence level of $95 \%$ it can be argued that the differences between the average values of the surface ridge and the ploughing depth, as well as between the variances of these indicators according to Fisher"s F-criterion, are of purely random nature.

\section{Conclusions}

1. Efficient increase in the smoothness of the movement of a modular agricultural aggregate is possible by throttling the hydraulic system of the rear suspension of the tractor. The value of the dissipative drag coefficient is directly proportional to the degree of throttling of the hydraulic system, and it varies within the range $0-1.80 \mathrm{kN} \cdot \mathrm{s} \cdot \mathrm{m}^{-1}$.

2. The desired nature of the normalised correlation functions and spectral characteristics of vertical oscillations of the block-modular agricultural aggregate is observed at the increase in the degree of throttling of the hydraulic system to $78 \%$. The operation of the block-modular aggregate with such a degree of throttling of the hydraulic system makes it possible to reduce the dispersion of its vertical oscillations by 3 times. The dispersion of oscillations in the tractive resistance of the plough is almost independent of the rigidity of the connection between the tractor and the technological module of the modular ploughing aggregate. The dispersion of the torque oscillations on the tractor power take-off shaft decreases by 10 times, with increasing rigidity, which makes it possible to increase the efficiency of the block-modular ploughing aggregate by $6 \%$ and reduce the specific fuel consumption by $12.4 \%$.

\section{References}

[1] Viesturs D., Kopiks N. Trends in development of tractor fleet in Latvia. Engineering for rural development, 2017, Vol.16, pp. 534-539.

[2] Belyaev N. Powerful and heavy-duty wheeled agricultural tractors abroad. Tractors and agricultural machinery. 1986, No 5, pp. 52-58. (In Russian).

[3] Bulgakov V., Nadykto V., Ivanovs S., Dukulis I. Improving the performance of a ploughing tractor by means of an auxiliary carriage with motorized axle. Journal of Agricultural Engineering. Vol. 52 (1), 2021, Art.1109

[4] Nadykto V. The role of modular power units in the formation of the type of tractors in Ukraine. Tractors and agricultural machinery. 2010, No 6. pp. 22-25. (In Russian).

[5] Simikić M., Dedović N., Savin L., Tomić M., Ponjičan O. Power delivery efficiency of a wheeled tractor at oblique drawbar force. Soil and Tillage Research, 141, 2014, pp. 32-43.

[6] Nadykto V., Kyurchev V., Chaplinskyi A. Ways to increase the traction efficiency of modular draft device. IOP Conference Series: Materials Science and Engineering, Volume 1021 (1), 2021, Art. 012043.

[7] Ivanovs S., Bulgakov V., Nadykto V., Ihnatiev Ye., Smolinskyi S., Kiernicki Z. Experimental study of the movement controllability of a machine-and-tractor aggregate of the modular type INMATEH - Agricultural Engineering. 2020, Vol. 61, No 2, pp. 9-16.

[8] Bulgakov V., Pascuzzi S., Ivanovs S., V. Nadykto, Nowak J. Kinematic discrepancy between driving wheels evaluated for a modular traction device. Biosystems Engineering. 2020, Vol. 196, pp. 88-96. 
[9] Bulgakov V., Aboltins A., Ivanovs S, Holovach I., Nadykto V., Beloev H. A mathematical model of plane-parallel movement of the tractor aggregate modular type. Agriculture. 2020, Nr.10(10) art.454.

[10] Sidorov M. Elastic-damping properties of the transport and technological module as part of an agricultural machine-tractor unit. International Research Journal. 2014. No 10-2 (41), pp. 119-121. (In Russian).

[11] Sam B., Kathirvel K. Development and evaluation of vibration isolators for reducing hand transmitted vibration of walking and riding type power tillers. Biosystems Engineering. 2009, 103 (4), pp. 427-437

[12] Yang J., Meng X. Study on vibration mechanism and measures for vibration reducing to the handle of cultivator by virtual prototype technology Nongye Jixie Xuebao/Transactions of the Chinese Society of Agricultural Machinery. 2005, 36 (2), pp. 39-42.

[13]ГОСТ 20915-2011. Методы определения условий испытаний. Испытания сельскохозяйственной техники (Standard 20915-2011. Testing of agricultural tractors and machines. Procedure for determination of test conditions), Moscow, 2011, 47 p. (In Russian)

[14] Доспехов Б. Методика полевого опыта (Methodology of field experiments). 2012. Moscow: Nauka, 352 pp. (In Russian)

[15] Веденяпин С.В. Общая методика экспериментальных исследований и обработки опытных данных (General methodology of experimental research and processing of experimental data), Москва: Колос, 1997, 159 p. (In Russian) 